\title{
PENGARUH DEBIT DALAM PROSES AERASI DENGAN METODE KOMBINASI LAHAN BASAH DALAM MENURUNKAN KADAR BOD DAN TSS PADA AIR LIMBAH RSUD DAYA KOTA MAKASSAR \\ Effect Of Debit In Aeration Process Using Wet Combination Method In Reducing Bod And Tss Levels In Waste Daya Kota Rsud Makassar Syamsuddin $\mathbf{S}^{1}$ \\ 1,2 Jurusan Kesehatan Lingkungan Poltekkes Kemenkes Makassar syam.kesling@gmail.com
}

\begin{abstract}
The hospital is a health care institution with a core activity services preventive, curative, rehabilitative and promotif. Such activities will generate positive and negative impacts. A positive impact is the increased degree of public health, while among other disruptive is the litter and waste both medical and non medical that can cause disease and pollution need to be per special-hatian. The purpose of this research was conducted to find out to find out the influence of discharge in the process of aeration and to know the process of aeration with the method of combination of the wetlands in the lower levels of the BOD and TSS, on waste water in the Provincial Hospital City of Makassar. The results of the BOD levels decrease contact time on 1 hour shows the results of the decline of $70.83 \%$ on first treatment while on the treatment of $42.48 \%$, and the second on a third treatments $14.16 \%$ this indicates that sewage treatment on levels of BOD with a decrease in good contrast to the second treatment with contact time 1.5 hours and first treatment with contact time 1 hour. TSS levels decrease contact time on 1 hour shows results drop in $40.66 \%$ on first treatment while on treatment second $7.66 \%$, and on a third treatments $1.66 \%$. From the results of this research, then it is advisable for the community so that it may be able to use the plant sprouts in daily activities to process domestic waste before it dumped kebadan the environment so that the environment is not polluted. For the Provincial Hospital Power Makassar city to be more attentive to the IPAL waste dumped into the body before the environment and methods on wetland outlet suggest in the room open and gets enough sunlight for the process of fotosintetis on plant water spinach
\end{abstract}

Key words: Liquid waste and aeration

\section{ABSTRAK}

Rumah sakit merupakan institusi pelayanan kesehatan dengan inti kegiatan pelayanan preventif, kuratif, rehabilitatif dan promotif. Kegiatan tersebut akan menimbulkan dampak positif dan negatif. Dampak positif adalah meningkatnya derajat kesehatan masyarakat, sedangkan dampak negatifnya antara lain adalah sampah dan limbah medis maupun non medis yang dapat menimbulkan penyakit dan pencemaran yang perlu per-hatian khusus. Tujuan penelitian ini dilakukan untuk mengetahui untuk mengetahui pengaruh debit dalam proses aerasi dan Untuk mengetahui proses aerasi dengan metode kombinasi Lahan basah dalam menurunkan kadar BOD dan TSS, pada air limbah di RSUD Daya Kota Makassar. Jenis penelitian ini adalah penelitian eksperimen pendekatan Pre post test dengan menggunakan metode memanfaatkan tanaman kangkung (ipomoea aquatic), denganjudulpenelitianyaitupengaruh proses aerasi dengan lahanbasah dalam menurunkan kadar BOD pada air limbah domestik di RSUD Daya kota Makassar. Hasil penurunan kadar BOD pada waktu kontak 1 jam menunjukan hasil penurunan $70,83 \%$ pada perlakuan pertama sedangkan pada perlakuan kedua $42,48 \%$, dan pada perlakuan ketiga $14,16 \%$ hal ini menunjukan bahwa pada pengolahan limbah kadar BOD dengan penurunan yang baik berbeda dengan perlakuan kedua dengan waktu kontak 1,5 jam dan perlakuan pertama dengan waktu kontak 1 jam. penurunan kadar TSS pada waktu kontak 1 jam menunjukan hasil penurunan $40,66 \%$ pada perlakuan pertama sedangkan pada perlakuan kedua $7,66 \%$, dan pada perlakuan ketiga 1,66\%. Dari hasil penelitian ini, maka disarankan Bagi masyarakat agar kiranya dapat menggunakan tanaman kangkung dalam aktivitas sehari-hari untuk mengolah limbah domestik sebelum dibuang kebadan lingkungan agar lingkungan sekitar tidak tercemar. Bagi RSUD Daya Kota Makassar agar lebih memperhatikan IPAL sebelum limbah dibuang ke badan lingkungan dan metode outlet wetland di sarankan diruangan terbuka serta mendapat cahaya matahari yang cukup untuk proses fotosintetis pada tanaman kangkung.

Keyword : Limbah cair dan aerasi

\section{PENDAHULUAN}

Lingkungan bagi manusia merupakan salah satu unsur yang sangat penting dalam kehidupannya, karena lingkungan tidak saja sebagai tempat manusia beraktivitas, tetapi lingkungan juga sangat berperan dalam mendukung berbagai aktivitas manusia. Di lingkungan, semua kebutuhan hidup manusia telah tersedia sehingga ada upaya yang telah dilakukan oleh manusia untuk mengeksploitasi lingkungannya demi hajat hidupnya. Karenanya merupakan merupakan hal yang sangat wajar bila interaksi manusia manusia dengan lingkungannya akan berlangsung secara berkelindan dan terus menerus. Sikap dan perilaku manusia akan menentukan baik buruknya kondisi suatu lingkungan. Sebaliknya, bagaimana manusia memperlakukan lingkungan dampaknya akan berpengaruh terhadap kualitas kehidupan manusia itu sendiri. (Syukri Hamzah 2013) 
Upaya meningkatkan derajat kesehatan masyarakat khususnya di kota-kota besar semakin meningkat pendirian rumah sakit (RS).Sebagai kualitas efluen limbah rumah sakit tidak memenuhi syarat.Limbah rumah sakit dapat mencemari lingkungan penduduk disekitar rumah sakit dan dapat menimbulkan masalah kesehatan.Hal ini dikarenakan dalam limbah rumah sakit dapat mengandung berbagai jasad renik penyebab penyakit pada manusia termasuk demam typoid, cholera, disentri dan hepatitis sehingga limbah harus diolah sebelum dibuang ke lingkungan.

Dalam kasus-kasus pencemaran perairan, baik itu laut, sungai, kanal, danau, maupun waduk, seringkali nilai BOD, COD peraiaran telah melebihi baku mutu akibat dari adanya aktifitas industri, perkantoran, pemukiman, perkebunan, perhotelan, yang menghasilkan limbah cair setiap hari dan akan dibuang tanpa pengolahan terlebih dahulu. Pencemaran lingkungan di Indonesia terutama pencemaran sungai, danau dan sarana perairan lainnya dalam beberapa tahun belakangan ini terus meningkat.

Sampah dan limbah rumah sakit adalah semua sampah dan limbah yang dihasilkan oleh kegiatan rumah sakit dan kegiatan penunjang lainnya.Secara umum sampah dan limbah rumah sakit dibagi dalam dua kelompok besar yaitu sampah atau limbah klinis dan domestik baik padat maupun cair.Selain sampah klinis, dari kegiatan penunjang rumah sakit juga menghasilkan sampah domestik atau dapat juga disebut sampah non medis. Sampah non medis ini biasa berasal dari kantor/administrasi kertas, unit pelayanan (berupa karton, kaleng, botol), samapah dari ruang pasien,sisa makanan buangan,sampah dapur (sisa pembungkus, sisa makanan/bahan makanan, sayur dan lainlain).limbah cair yang dihasilkan rumah sakit memiliki karakteristik tertentui baik secara fisik,kimia dan biologis. (Asmadi 2013).

\section{METODE}

Pada penelitian ini bak penampungan dengan volume 20 I di isi dengan limbah kemudian hitung debit sebelum mengalirkan air limbah saat proses pengolahan karena semakin lambat debit yang mengalir maka semakin baik proses pengolahan, karena debit aliran mempengaruhi proses aerasi, setelah debit air di tentukan buka kran inlet lalu biarkan air mengalir pada pipa yang panjangnya 1 meter dan menuju pada pipa aerasi dengan panjang 1 meter yang sudah dilubangi, biarkan limbah mengalami proses aerasi pada pipa aerasi (water walls), Dimana jarak ketinggian antara pipa dan lahan basah 1,5 meter sehingga air limbah mengalami kontak dengan udara dan terjadi proses aerasi dan mengalir menuju lahan basah, dimana proses aerasi bertujuan untuk meningkatkan konsentrasi oksigen didalam air limbah untuk meningkatkan kontak antara air limbah dengan udara sehingga dapat memberikan manfaat dalam pengolahan air limbah yang mengalir menuju lahan basah, dimana air yang mengalir menuju lahan basah mencapai jumlah volume sebesar 20 I pada setiap debit yang sudah ditentukan sehingga proses pengolahan pada lahan basah yang sudah ditanami tanaman kangkung dan mengalami proses vtioremediasi pada akar dari tanaman kangkung yang menyerap atau memakan mikroorganisme yang ada pada limbah

Penelitian ini dilakukan di wilayah RSUD Daya kota Makassar dengan melakukan pengambilan sampel limbah domestik Rumah Sakit. Lokasi pengolahan dilakukan di workshop pengolahan limbah kampus Kesehatan Lingkungan Poltekkes Kemenkes Makassar. Lokasi Pemeriksaan/ identifikasi yaitu Laboratorium mikrobiologi dan kimia kampus kesehatan lingkungan Poltekkes Kemenkes Makassar

\section{Pengolahan dan analisis data}

Data yang diperoleh dari hasil pemeriksaan laboratotium diolah dengan melakukan uji statistic pada computer kemudian disajikan dalam bentuk table dan dianalisis untuk mengetahui besarnya penurunan kadar BOD pada air limbah domestik RSUD Daya Kota Makassar setelah pengolahan dengan aerasi dan metode lahan basah dengan variasi waktu dan dihubungkan dengan peraturan surat keputusan Gubernur Sulawesi Selatan No. 69 tahun 2010. 
Jurnal Sulolipu : Media Komunikasi Sivitas Akademika dan Masyarakat

Vol.18 No.I 2018

e-issn : 2622-6960, p-issn : 0854-624X

\section{HASIL}

1. Hasil pengolahan BOD dengan waktu kontak 1 jam

Tabel 1

Hasil pengolahan BOD pada air limbah di RSUD Daya Kota Makassar dengan waktu kontak 1 jam tahun 2017

\begin{tabular}{|c|c|c|c|c|c|}
\hline \multirow{2}{*}{$\begin{array}{l}\mathbf{N} \\
\mathbf{O}\end{array}$} & \multirow{2}{*}{$\begin{array}{l}\text { Kode } \\
\text { sampel }\end{array}$} & \multicolumn{2}{|c|}{$\begin{array}{c}\text { Uraian } \\
\text { pemeriksaan BOD }\end{array}$} & \multirow{2}{*}{$\begin{array}{l}\text { Waktu } \\
\text { kontak }\end{array}$} & \multirow{2}{*}{$\begin{array}{c}\text { Persenta } \\
\text { se } \\
\text { penuruna } \\
\text { n BOD }\end{array}$} \\
\hline & & Sebelum & Sesudah & & \\
\hline 1 & 6.3 & $135 \mathrm{mg} / \mathrm{l}$ & $\begin{array}{l}97,5 \\
\mathrm{mg} / \mathrm{l}\end{array}$ & $\begin{array}{l}08.00- \\
09.00\end{array}$ & $27,77 \%$ \\
\hline 2 & 6.2 & $135 \mathrm{mg} / \mathrm{l}$ & $60 \mathrm{mg} / \mathrm{l}$ & $\begin{array}{l}09.00- \\
10.00\end{array}$ & $55,55 \%$ \\
\hline 3 & 6.1 & $135 \mathrm{mg} / \mathrm{l}$ & $55 \mathrm{mg} / \mathrm{l}$ & $\begin{array}{c}10.00- \\
11.00\end{array}$ & $59,25 \%$ \\
\hline
\end{tabular}

2. Hasil pengolahan BOD dengan kontak waktu 1,5 jam

Tabel 2

Hasil pengolahan BOD pada air limbah di RSUD Daya

Kota Makassar dengan kontak waktu 1,5 jam Tahun2017

\begin{tabular}{|c|c|c|c|c|c|}
\hline \multirow{2}{*}{$\begin{array}{l}\mathbf{N} \\
\mathbf{O}\end{array}$} & \multirow{2}{*}{$\begin{array}{c}\text { Kode } \\
\text { sampe } \\
\text { I }\end{array}$} & \multicolumn{2}{|c|}{$\begin{array}{c}\text { Uraian pemeriksaan } \\
\text { BOD }\end{array}$} & \multirow{2}{*}{ Waktu } & \multirow{2}{*}{$\begin{array}{c}\text { Persenta } \\
\text { se } \\
\text { penurun } \\
\text { an BOD }\end{array}$} \\
\hline & & Sebelum & Sesudah & & \\
\hline 1 & 4.1 & $135 \mathrm{mg} / \mathrm{l}$ & $37,5 \mathrm{mg} / \mathrm{l}$ & $\begin{array}{l}08.00- \\
09.30\end{array}$ & $72,22 \%$ \\
\hline 2 & 4.2 & $135 \mathrm{mg} / \mathrm{l}$ & $45 \mathrm{mg} / \mathrm{l}$ & $\begin{array}{l}09.30- \\
11.00\end{array}$ & $66,66 \%$ \\
\hline 3 & 4.3 & 135 mg/l & 45 mg/l & $\begin{array}{l}12.00- \\
30.00\end{array}$ & $66,66 \%$ \\
\hline
\end{tabular}

\section{Hasil pengolahan BOD dengan kontak} waktu 5 jam

Tabel 3

Hasil pengolahan BOD pada air limbah di RSUD Daya Kota Makassar dengan kontak waktu 5 jam Tahun 2017

\begin{tabular}{|c|c|c|c|c|c|}
\hline \multirow{2}{*}{$\begin{array}{l}N \\
0\end{array}$} & \multirow{2}{*}{$\begin{array}{l}\text { Kode } \\
\text { sampel }\end{array}$} & \multicolumn{2}{|c|}{$\begin{array}{c}\text { Uraian pemeriksaan } \\
\text { BOD }\end{array}$} & \multirow{2}{*}{ Waktu } & \multirow{2}{*}{$\begin{array}{c}\text { Persentas } \\
\mathrm{e} \\
\text { penuruna } \\
\mathrm{n} \text { BOD }\end{array}$} \\
\hline & & Sebelum & Sesudah & & \\
\hline 1 & 2.3 & $135 \mathrm{mg} / \mathrm{l}$ & $10 \mathrm{mg} / \mathrm{l}$ & $\begin{array}{l}08.00- \\
13.00\end{array}$ & $92,59 \%$ \\
\hline 2 & 2.2 & $135 \mathrm{mg} / \mathrm{l}$ & $\begin{array}{l}22,5 \\
\mathrm{mg} / \mathrm{l}\end{array}$ & $\begin{array}{l}13.00- \\
18.00\end{array}$ & $83,33 \%$ \\
\hline 3 & 2.1 & $135 \mathrm{mg} / \mathrm{l}$ & $10 \mathrm{mg} / \mathrm{l}$ & $\begin{array}{l}18.00- \\
23.00\end{array}$ & $92,59 \%$ \\
\hline
\end{tabular}

\section{Hasil Rata- rata pengolahan BOD}

Tabel 4

Hasil Rata- rata pengolahan BOD pada air limbah di RSUD Dayan Kota Makassar Tahun 2017

\begin{tabular}{|c|c|c|c|c|c|}
\hline \multirow{2}{*}{$\begin{array}{l}\mathrm{N} \\
\mathrm{O}\end{array}$} & \multirow{2}{*}{$\begin{array}{l}\text { Kode } \\
\text { sampel }\end{array}$} & \multicolumn{2}{|c|}{$\begin{array}{c}\text { Uraian pemeriksaan } \\
\text { BOD }\end{array}$} & \multirow{2}{*}{$\begin{array}{l}\text { Waktu } \\
\text { kontak }\end{array}$} & \multirow{2}{*}{$\begin{array}{c}\text { Persenta } \\
\text { se } \\
\text { penurun } \\
\text { an } B O D\end{array}$} \\
\hline & & $\begin{array}{c}\text { Sebelu } \\
\mathrm{m}\end{array}$ & Sesudah & & \\
\hline 1 & 6.1 & $\begin{array}{l}135 \\
\mathrm{mg} / \mathrm{l}\end{array}$ & $\begin{array}{c}70,83 \\
\mathrm{mg} / \mathrm{l}\end{array}$ & 1 jam & $47,53 \%$ \\
\hline 2 & 4.1 & $\begin{array}{c}135 \\
\mathrm{mg} / \mathrm{l}\end{array}$ & $42,48 \mathrm{mg} / \mathrm{l}$ & 1,5 jam & $68,53 \%$ \\
\hline 3 & 2.1 & $\begin{array}{l}135 \\
\mathrm{mg} / \mathrm{l}\end{array}$ & $\begin{array}{c}14,16 \\
\mathrm{mg} / \mathrm{l}\end{array}$ & 5 jam & $89,51 \%$ \\
\hline
\end{tabular}

\section{Hasil pengolahan TSS pada air limbah dengan kontak waktu 1 jam}

Tabel 5

Hasil pengolahan TSS pada air limbah di RSUD Daya Kota Makassar dengan kontak waktu 1 jam Tahun 2017

\begin{tabular}{cccccc} 
& Kode & \multicolumn{2}{c}{$\begin{array}{c}\text { Uraian pemeriksaan } \\
\text { NSS }\end{array}$} & $\begin{array}{c}\text { Waktu } \\
\text { sampel }\end{array}$ & \multicolumn{3}{c}{$\begin{array}{c}\text { Persentase } \\
\text { penurunan } \\
\text { TSS }\end{array}$} \\
\cline { 3 - 4 } & & Sebelum & Sesudah & \\
\hline $\mathbf{1}$ & 6.1 & $65 \mathrm{mg} / \mathrm{l}$ & $40 \mathrm{mg} / \mathrm{l}$ & $\begin{array}{r}08.00- \\
09.00\end{array}$ & $38,46 \%$ \\
\hline $\mathbf{2}$ & 6.2 & $65 \mathrm{mg} / \mathrm{l}$ & $38 \mathrm{mg} / \mathrm{l}$ & $\begin{array}{r}09.00- \\
10.00\end{array}$ & $41,53 \%$ \\
\hline $\mathbf{3}$ & 6.3 & $65 \mathrm{mg} / \mathrm{l}$ & $44 \mathrm{mg} / \mathrm{l}$ & $\begin{array}{c}10.00- \\
11.00\end{array}$ & $32,30 \%$ \\
\hline
\end{tabular}

\section{Hasil pengolahan TSS dengan waktu} kontak 1,5 jam

Tabel 6

Hasil pengolahan TSS pada air limbah di RSUD Daya Kota Makassar dengan waktu kontak 1,5 jam Tahun 2017

\begin{tabular}{|c|c|c|c|c|c|}
\hline \multirow{2}{*}{$\begin{array}{l}\mathbf{N} \\
\mathbf{O}\end{array}$} & \multirow{2}{*}{$\begin{array}{l}\text { Kode } \\
\text { sampe } \\
\text { I }\end{array}$} & \multicolumn{2}{|c|}{$\begin{array}{c}\text { Uraian } \\
\text { pemeriksaan TSS }\end{array}$} & \multirow{2}{*}{$\begin{array}{c}\text { Waktu } \\
\text { konta } \\
\mathbf{k}\end{array}$} & \multirow{2}{*}{$\begin{array}{c}\text { Persenta } \\
\text { se } \\
\text { penurun } \\
\text { an TSS }\end{array}$} \\
\hline & & $\begin{array}{c}\text { Sebelu } \\
\mathrm{m}\end{array}$ & $\begin{array}{c}\text { sesuda } \\
\mathrm{h}\end{array}$ & & \\
\hline 1 & 4.1 & $65 \mathrm{mg} / \mathrm{l}$ & $4 \mathrm{mg} / \mathrm{l}$ & $\begin{array}{l}08.00- \\
09.30\end{array}$ & $93,84 \%$ \\
\hline 2 & 4.2 & $65 \mathrm{mg} / \mathrm{l}$ & $9 \mathrm{mg} / \mathrm{l}$ & $\begin{array}{l}09.30- \\
11.00\end{array}$ & $86,15 \%$ \\
\hline 3 & 4.3 & $65 \mathrm{mg} / \mathrm{l}$ & $8,2 \mathrm{mg} / \mathrm{l}$ & $\begin{array}{l}11.00- \\
12.30\end{array}$ & $87,38 \%$ \\
\hline
\end{tabular}


Jurnal Sulolipu : Media Komunikasi Sivitas Akademika dan Masyarakat

Vol.18 No.I 2018

e-issn : 2622-6960, p-issn : 0854-624X

\section{Hasil pengolahan TSS dengan waktu kontak 5 jam}

Tabel 7

Hasil pengolahan TSS pada air limbah di RSUD Daya Kota Makassar dengan waktu kontak 5 jam Tahun 2017

\begin{tabular}{|c|c|c|c|c|c|}
\hline \multirow{2}{*}{$\begin{array}{l}\mathrm{N} \\
\mathrm{O}\end{array}$} & \multirow{2}{*}{$\begin{array}{l}\text { Kode } \\
\text { sampe } \\
\text { I }\end{array}$} & \multicolumn{2}{|c|}{$\begin{array}{c}\text { Uraian } \\
\text { pemeriksaan TSS }\end{array}$} & \multirow{2}{*}{$\begin{array}{c}\text { Waktu } \\
\text { konta } \\
\mathbf{k}\end{array}$} & \multirow{2}{*}{$\begin{array}{c}\text { Persenta } \\
\text { se } \\
\text { penurun } \\
\text { an TSS }\end{array}$} \\
\hline & & $\begin{array}{c}\text { Sebelu } \\
\text { m }\end{array}$ & $\begin{array}{c}\text { Sesuda } \\
\text { h }\end{array}$ & & \\
\hline 1 & 2.1 & $65 \mathrm{mg} / \mathrm{l}$ & $2 \mathrm{mg} / \mathrm{l}$ & $\begin{array}{l}08.00- \\
13.00\end{array}$ & $96,92 \%$ \\
\hline 2 & 2.2 & $65 \mathrm{mg} / \mathrm{l}$ & $1 \mathrm{mg} / \mathrm{l}$ & $\begin{array}{c}13.00- \\
18.00\end{array}$ & $98,46 \%$ \\
\hline 3 & 2.3 & $65 \mathrm{mg} / \mathrm{l}$ & $2 \mathrm{mg} / \mathrm{l}$ & $\begin{array}{l}18.00- \\
23.00\end{array}$ & $96,92 \%$ \\
\hline
\end{tabular}

\section{Hasil Rata- rata pengolahan TSS pada air} limbah

Tabel 8

Hasil Rata- rata pengolahan TSS pada air limbah di RSUD Dayan Kota Makassar Tahun 2017

\begin{tabular}{|c|c|c|c|c|c|}
\hline \multirow{2}{*}{$\begin{array}{l}\mathrm{N} \\
\mathrm{O}\end{array}$} & \multirow{2}{*}{$\begin{array}{c}\text { Kode } \\
\text { samp } \\
\text { el }\end{array}$} & \multicolumn{2}{|c|}{$\begin{array}{c}\text { Uraian } \\
\text { pemeriksaan TSS }\end{array}$} & \multirow{2}{*}{$\begin{array}{c}\text { Wak } \\
\text { tu } \\
\text { kont } \\
\text { ak }\end{array}$} & \multirow{2}{*}{$\begin{array}{c}\text { Persent } \\
\text { ase } \\
\text { penurun } \\
\text { an TSS }\end{array}$} \\
\hline & & $\begin{array}{c}\text { Sebelu } \\
\mathrm{m}\end{array}$ & $\begin{array}{c}\text { Sesuda } \\
h\end{array}$ & & \\
\hline 1 & 6.1 & $65 \mathrm{mg} / \mathrm{l}$ & $\begin{array}{c}40,66 \\
\mathrm{mg} / \mathrm{l}\end{array}$ & $\frac{1}{\text { jam }}$ & $47,53 \%$ \\
\hline 2 & 4.1 & $65 \mathrm{mg} / \mathrm{l}$ & $7,66 \mathrm{mg} / \mathrm{l}$ & $\begin{array}{l}1,5 \\
\text { jam }\end{array}$ & $68,53 \%$ \\
\hline 3 & 2.1 & $6 \mathrm{mg} / \mathrm{l}$ & $\begin{array}{l}1,66 \\
\mathrm{mg} / \mathrm{l}\end{array}$ & $\begin{array}{c}5 \\
\text { jam }\end{array}$ & $89,51 \%$ \\
\hline
\end{tabular}

\section{PEMBAHASAN}

Sampel awal adalah $135 \mathrm{mg} / \mathrm{l}$ dan kadar TSS $65 \mathrm{mg} / \mathrm{l}$. Penelitian awal atau perlakuan pertama dilaksanakan pada tanggal 15 maret, jam 8 pagi sampai dengan jam 11 malam. Jumlah sampel air limbah yang digunakan dalam penelitian ini yaitu 60 liter dan dilakukan 3 kali pengulangan setiap 5 jamnya. Perlakuan kedua dilaksanakan pada tanggal 16 maret, jam 8 sampai jam 12.30 dilakukan 3 kali pengulangan setiap 1 jam 30 menit, perlakuan yang ketiga sama dengan perlakuan sebelumnya pada tanggal 17 maret, dengan tiga kali pengulangan disetiap 1 jam. Pada eksperimen ini sampel limbah diolah melalui kombinasi lahan basah dengan proses aerasi dengan lahan basah

Penelitian tentang Pengaruh proses aerasi dengan lahan basah dalam menurunkan kadar BOD dan TSS pada air limbah RSUD Daya kota Makassar, dengan kegiatan meliputi analisis kadar BOD dan TSS melalui pengaruh aerasi dengan lahan basah menggunakan tanaman kangkung air (Iphomea aquatical). Sampel air di ambil di RSUD Daya kota Makassar dan penelitian dilakukan di workshop dan laboratorium air kampus Kesehatan Lingkungan.

Dari hasil penelitian yang telah dilakukan dengan pengaruh aerasi dengan lahan basah dalam menurunkan kadar BOD dan TSS pada air limbah di RSUD Daya Kota Makassar dimana hasil yang telah dicapai dapat dilihat pada tabel 1 sampai tabel 6.

Kadar BOD awal pada pemeriksaan awal yaitu sebesar $135 \mathrm{mg} / \mathrm{l}$ dan kadar TSS 65 mg/l sebelum pengolahan sedangkan Analisis $\mathrm{pH}$ dan suhu pada penelitian ini menggunakan alat $\mathrm{pH}$ dan suhu dengan hasil $\mathrm{pH} 7$ sedangkan suhu yaitu $28^{\circ} \mathrm{C}$, sehingga hasil dalam pengolahan BOD dan TSS dapat memberikan dampak yang positif terhadap pengolahan limbah karena jumlah $\mathrm{pH}$ dan suhu normal,berdasarkan pada penelitian sebelumnya yang berjudul "proses aerasi dengan lahan basah dalam menurunkan kadar BOD pada air kanal panampu"menunjukan hasil yang baik pada proses pengolahannya karena di dukung dengan jumlah $\mathrm{pH}$ dan suhu yang normal.

Kadar BOD dengan penurunan 20,83 mg,I (84,57\%) pengolahan pada percobaan pertama $14,16 \mathrm{mg} / \mathrm{l}$ dan percobaan kedua 42,48 $\mathrm{mg} / \mathrm{l}$, percobaan ketiga 70,83 $\mathrm{mg} / \mathrm{l}$ dan besar penurunan $127,47 \mathrm{mg} / \mathrm{l}$, dari hasil pemeriksaan kadar sampel awal dari setiap perlakuan mengalami perbedaan. hal ini dikarenakan perbedaan waktu pengambilan sampel. Pada perlakuan pertama pengambilan sampel dilakukan pada sore hari, perlakuan ke 2 dan ke 3 dilakukan pada pagi hari, dimana pada pengambilan sampel ke 2 dan 3 terjadi pengenceran karena faktor cuaca (setelah hujan) dan aktivitas yang dilakukan pada pagi hari lebih banyak hingga menyebabkan bertambahnya volume limbah serta bahan pencemar yang masuk ke penampungan limbah RSUD Daya Kota Makassar.

Tingginya rata-rata kandungan BOD air limbah RSUD Daya Kota Makassar di karenakan adanya pengaruh zat-zat organik yang tinggi akibat dari berbagai limbah yang dihasilkan oleh pihak RSUD Daya Kota Makassar yang bersumber dari ,kamar mandi,tempat laundry, dan dapur RSUD Daya Kota Makassar contohnya,sisa-sisa sayuran, buah-buahan, dan sisa makanan,oleh karena bahan buangan bahan organik dapat membusuk atau terdegradasi oleh mikroorganisme sehingga menyebabkan kebutuhan bakteri akan oksigen terlarut akan bertambah pula untuk mengkonsumsi zat-zat organik, akibatnya kandungan BOD dalam air 
Jurnal Sulolipu : Media Komunikasi Sivitas Akademika dan Masyarakat

Vol.18 No.I 2018

e-issn : 2622-6960, p-issn : 0854-624X

limbah RSUD Daya Kota Makassar akan meningkat.

1) Pengolahan limbah domestik dalam menurunkan BOD dengan kontak waktu 1 jam, dengan lahan basah dalam menurunkan kadar BOD pada air limbah di RSUD Daya Kota Makassar

Berdasarkan Tabel 5.4 dan gambar 5.4 tentang hasil pengolahan BOD dengan waktu kontak 1 jam dari sampel awal BOD tersebut $135 \mathrm{mg} / \mathrm{l}$ mengalami penurunan $64,17 \mathrm{mg} / \mathrm{l}$ atau $47,53 \%$ sehingga menghasilka kadar BOD 70,83 mg/l dengan melalui 3 replikasi penyaringan $\mathrm{BOD}$ pada replikasi pertama mengalami penurunan dengan hasil $97,5 \mathrm{mg} / \mathrm{l}$,replikasi kedua mengalami penurunan dengan hasil $60 \mathrm{mg} / \mathrm{l}$ dan replikasi ketiga mengalami penurunan dengan hasil $55 \mathrm{mg} / \mathrm{l}$. berbeda dengan replikasi pertama dimana hasil dari pengolahan BOD lebih tinggi dari replikasi kedua, setelah melalui proses pengolahan mengalami penurunan kembali dengan hasil $55 \mathrm{mg} / \mathrm{l}$ lebih rendah dari replikasi pertama dan kedua. Pada akhir waktu penjenuhan tanaman kangkung selama 1 jam pada perlakuan ketiga tepatnya pada tanggal 15 maret 2017 kondisi kangkung tersebut mulai terlihat layu pada sebagian tanaman,tetapi terjadi pertumbuhan tunas baru walaupun pertumbuhannya tidak lebat atau memenuhi seluruh wadah/bak. Pertumbuhan kangkung menjadi terbatas karena luas wadah yang kecil. Sehingga menghambat pertumbuhan tanaman.

Tanaman yang terlalu banyak dalam wadah tersebut, akan mengakibatkan tanaman berkompetisi dalam mencari makanan diwadah atau lahan basah selain itu tanaman yang digunakan dalam penelitianini merupakan tanaman kangkung liar (tanaman merambat) yang pertumbuhannya baik atau yang mendapatkan asupan nutrisi yang dibutuhkan oleh tanaman kangkung seperti fosfat,carbon, nitrogen terjadinya. penurunan kualitas air limbah yang telah mengalami pengolahan secara fisik yaitu berbau dan berwarna (kuning kehijauan) hal tersebut dipengaruhi oleh proses penyerapan kangkung terhadap zat pencemar yang berlebihan sehingga daunnya menjadi layu dan mati. Daun tersebut terdekomposisi oleh mikro organisme dalam air dan sebagiannya menjadi tempat perkembang biakan bakteri.dengan adanya proses tersebut maka terjadi perubahan warna pada air dan menimbulkan bau yang tak sedap pada air tersebut.peristiwa tersebut terjadi selama proses bioremediasi, mempengaruhi aktifitas mikroba dalam mendekomposisi zat-zat pencemar kimiawi khususnya pada ketersediaan oksigen,pada tanaman yang memiliki jumlah akar yang jauh lebih banyak dan susunan sangat rapat akan berpengaruh pada oksigen yang disalurkan akar ke air akan lebih banyak pula.

Berdasarkan baku mutu limbah cair domestik, peraturan Gubernur Sulawesi Selatan no. 69 Tahun 2010 tentang baku mutu limbah cair domestik kategori B dan kerusakan lingkungan hidup adalah 40mg/l, sedangkan hasil penelitian kadar BOD yang dilakukan dengan waktu kontak 1 jam, analisa dari hasil pengolahan yang telah dilakukan pada waktu kontak 1 jam, tidak memenuhi syarat dan hanya mengalami penurunan kadar BOD dengan $52,47 \%$ dengan waktu kontak 1 jam.

Dalam proses pengolahan kadar BOD menerangkan bahwa kangkung yang digunakan dalam pengolahan dengan proses lahan basah dapat menurunkan kadar BOD sebesar $52,47 \%$ dari sampel awal yang ada pada limbah domestik RSUD Daya Kota Makassar.

2) Pengolahan limbah domestik dalam menurunkan BOD dengan kontak waktu 1,5 jam, dengan lahan basah dalam menurunkan kadar BOD pada air limbah di RSUD Daya Kota Makassar

Berdasarkan Tabel 5.4 dan gambar 5.4 tentang hasil pengolahan BOD dengan waktu kontak 1,5 jam dari sampel awal BOD tersebut $135 \mathrm{mg} / \mathrm{l}$ mengalami penurunan 92,42 $\mathrm{mg} / \mathrm{l}$ atau $68,33 \%$ sehingga menghasilkan kadar BOD $42,48 \mathrm{mg} / \mathrm{l}$ dengan melalui 3 replikasi penyaringan BOD pada replikasi pertama mengalami penurunan dengan hasil 37,5 $\mathrm{mg} / \mathrm{l}$,replikasi kedua mengalami penurunan dengan hasil $45 \mathrm{mg} / \mathrm{l}$ dan replikasi ketiga juga mengalami penurunan dengan hasil $45 \mathrm{mg} / \mathrm{l}$. berbeda dengan replikasi pertama dimana hasil dari pengolahan BOD lebih tinggi dari replikasi kedua dan ketiga, setelah melalui proses pengolahan mengalami penurunan kembali dengan hasil $45 \mathrm{mg} / \mathrm{l}$.hal ini didukung dengan kondisi tanaman 
kangkung pada wadah tersebut khususnya pada perlakuan ketiga daunnya tidak terlalu lebat dibandingkan dengan perlakuan kedua, tanaman kangkung tersebut mengalami pertumbuhan kangkung yang baik serta memunculkan tunas-tunas yang baru.selama perlakuan ketiga berlangsung tunas yang tumbuh sebanyak lima ruas sebagai hasil proses fotosintetis tanaman kangkung setelah menyerap unsur hara yang terkandung dalam limbah, proses penurunan kadar BOD pada kontak 1,5 jam. Terjadi karena adanya bantuan aerasi (waterfalls) serta pertumbuhan kangkung yang baik atau asupan nutrisinya terpenuhi,hal ini dengan ditunjukkan tumbuhnya tunas yang baru keluar dari ruasruas kangkung tersebut.sedangkan daun yang lama mulai layu dan bahkan mati.

Berdasarkan baku mutu limbah cair domestik, peraturan Gubernur Sulawesi Selatan no. 69 Tahun 2010 tentang baku mutu limbah cair domestik kategori B dan kerusakan lingkungan hidup adalah $40 \mathrm{mg} / \mathrm{l}$ sedangkan hasil penelitian kadar BOD yang dilakukan dengan waktu kontak 1,5jam, analisa dari hasil pengolahan yang telah dilakukan pada waktu kontak 1,5jam,tidak memenuhi syarat dan hanya mengalami penurunan kadar BOD dengan persentase $31,47 \%$ dengan waktu kontak 1,5 jam.

Dalam proses pengolahan kadar BOD menerangkan bahwa kangkung yang digunakan dalam pengolahan dengan proses lahan basah dapat menurunkan kadar BOD sebesar $31,47 \%$ dari sampel awal $135 \mathrm{mg} / \mathrm{l}$ pada limbah domestik RSUD Daya Kota Makassar.

3) Pengolahan limbah domestik dalam menurunkan BOD dengan waktu kontak 5 jam, dengan lahan basah dalam menurunkan kadar BOD pada air limbah di RSUD Daya Kota Makassar

Berdasarkan Tabel 5.4 dan gambar 5.4 tentang hasil pengolahan BOD dengan waktu kontak 5 jam dari sampel awal BOD tersebut $135 \mathrm{mg} / \mathrm{l}$ mengalami penurunan $120,84 \mathrm{mg} / \mathrm{l}$ atau 89,51 \% sehingga menghasilkan kadar BOD 14,16 mg/l, dengan melalui 3 replikasi pengolahan BOD pada replikasi pertama mengalami penurunan dengan hasil $10 \mathrm{mg} / \mathrm{l}$, pada replikasi kedua mengalami penurunan dengan hasil $22,5 \mathrm{mg} / \mathrm{l}$ dan pada replikasi ketiga mengalami penurunan kembali dengan hasil $10 \mathrm{mg} / \mathrm{l}$ dengan waktu kontak 5 jam cukup baik dalam menurunkan kadar BOD hal ini terlihat pada perlakuan kedua dan dan pertama terjadi penurunan dari kadar BOD pada sampel awal RSUD Daya Kota Makassar 135mg/l dan setelah pengolahan sebesar $14,16 \mathrm{mg} / \mathrm{l}$, hal ini disebabkan karena waktu kontak 5 jam dan penggunaan tanaman kangkung air yang akarnya terdapat mikroba rhizosfer untuk menguraikan benda-benda organik atau anorganik,selain itu dalam wadah lahan basah terjadi aktivitas pengolahan seperti sedimentasi, filtrasi, gas transfer, adsorpsi, dan pengolahan kimiawi dan biologis karena aktivitas organisme yang yang merekat pada akar tanaman kangkung.

Sekaitan dengan penelitian ini, penggunaan tanaman kangkung air merupakan tempat terjadinya aktivitas pertukaran gas didalam air sehingga secara tidak langsung mempengaruhi kadar BOD di air.

Tanaman ini merupakan gulma air emergent (tanaman air yang tergenang) mempunyai jaringan aerenchyma (jaringan yang diisi udara) yang berfungsi supaya gulma air ini bisa hidup pada kondisi anaerobic atau anoxic. (kurniadie,2011).

Berdasarkan baku mutu limbah cair domestik, peraturan Gubernur Sulawesi Selatan no. 69 Tahun 2010 tentang baku mutu limbah cair domestik kategori B dan kerusakan lingkungan hidup adalah $40 \mathrm{mg} / \mathrm{l}$.sedangkan hasil penelitian kadar BOD yang dilakukan dengan waktu kontak 5 jam, analisa dari hasil pengolahan yang telah dilakukan pada waktu kontak 5 jam, memenuhi syarat dan mampu menurunkan kadar BOD $89,51 \%$ dengan waktu kontak 5 jam.

Dalam proses pengolahan kadar BOD menerangkan bahwa kangkung yang digunakan dalam pengolahan dengan proses lahan basah dapat menurunkan kadar BOD sebesar $89,51 \%$ dari sampel awal yang ada pada limbah domestik RSUD Daya Kota Makassar.

4) Pengolahan limbah domestik dalam menurunkan TSS dengan kontak waktu 1 jam, dengan lahan basah dalam menurunkan kadar TSS pada air limbah di RSUD Daya Kota Makassar

Berdasarkan Tabel 5.5 dan gambar 
5.5 tentang hasil pengolahan TSS dengan waktu kontak 1 jam dari sampel awal TSS tersebut $65 \mathrm{mg} / \mathrm{l}$ mengalami penurunan sebesar $24,34 \mathrm{mg} / \mathrm{l}$ atau $37,44 \%$ sehingga menghasilkan kadar TSS 40,66 mg/l dengan melalui 3 replikasi penyaringan TSS pada replikasi pertama dengan hasil 40 $\mathrm{mg} / \mathrm{l}$,replikasi kedua dengan hasil $38 \mathrm{mg} / \mathrm{l}$ dan replikasi ketiga dengan hasil $44 \mathrm{mg} / \mathrm{l}$.

Berdasarkan baku mutu limbah cair domestik, peraturan Gubernur Sulawesi Selatan no. 69 Tahun 2010 tentang baku mutu limbah cair domestik kategori B dan kerusakan lingkungan hidup adalah $35 \mathrm{mg} / \mathrm{l}$.sedangkan hasil penelitian kadar TSS yang dilakukan dengan waktu kontak 1 jam, analisa dari hasil pengolahan yang telah dilakukan pada waktu kontak 1 jam, tidak memenuhi syarat dan hanya mengalami penurunan kadar TSS $37,44 \%$ dengan waktu kontak 1 jam.

Dalam proses pengolahan kadar TSS menerangkan bahwa kangkung yang digunakan dalam pengolahan dengan proses lahan basah dapat menurunkan kadar TSS sebesar $37,44 \%$ dari sampel awal yang ada pada limbah domestik RSUD Daya Kota Makassar.

5) Pengolahan limbah domestik dalam menurunkan TSS dengan kontak waktu 1,5 jam, dengan lahan basah dalam menurunkan kadar TSS pada air limbah di RSUD Daya Kota Makassar

Berdasarkan Tabel 5.6 dan gambar 5.6 tentang hasil pengolahan TSS dengan waktu kontak 1,5 jam dari sampel awal TSS tersebut $65 \mathrm{mg} / \mathrm{l}$ mengalami penurunan 57,34 $\mathrm{mg} / \mathrm{l}$ atau $88,21 \%$ sehingga menghasilkan kadar TSS 7,66 mg/l dengan melalui 3 replikasi penyaringan TSS pada replikasi pertama dengan hasil $4 \mathrm{mg} / \mathrm{l}$,replikasi kedua dengan hasil $9 \mathrm{mg} / \mathrm{l}$ dan replikasi pertama dengan hasil 8,2 mg/l.

Berdasarkan baku mutu limbah cair domestik, peraturan Gubernur Sulawesi Selatan no. 69 Tahun 2010 tentang baku mutu limbah cair domestik kategori B dan kerusakan lingkungan hidup adalah $35 \mathrm{mg} / \mathrm{l}$.sedangkan hasil penelitian kadar TSS yang dilakukan dengan waktu kontak 1,5 jam, analisa dari hasil pengolahan yang telah dilakukan pada waktu kontak 1,5 jam, memenuhi syarat dan mampu menurunkan kadar TSS $88,21 \%$ dengan waktu kontak 1,5 jam.
Dalam proses pengolahan kadar TSS menerangkan bahwa kangkung yang digunakan dalam pengolahan dengan proses lahan basah dapat menurunkan kadar TSS sebesar $88,21 \%$ dari sampel awal yang ada pada limbah domestik RSUD Daya Kota Makassar.

6) Pengolahan limbah domestik dalam menurunkan TSS dengan kontak waktu 5 jam, dengan lahan basah dalam menurunkan kadar TSS pada air limbah di RSUD Daya Kota Makassar

Berdasarkan Tabel 5.7 dan gambar 5.7 tentang hasil pengolahan TSS dengan waktu kontak 5 jam dari sampel awal TSS tersebut $65 \mathrm{mg} / \mathrm{l}$ mengalami penurunan sebesar 63,34 sehingga menghasilkan kadar kadar TSS 1,66 mg/l dengan melalui 3 replikasi penyaringan TSS pada replikasi pertama dengan hasil $2 \mathrm{mg} / \mathrm{l}$,replikasi kedua dengan hasil $1 \mathrm{mg} / \mathrm{l}$ dan replikasi ketiga dengan hasil $2 \mathrm{mg} / \mathrm{l}$.

Berdasarkan baku mutu limbah cair domestik, peraturan Gubernur Sulawesi Selatan no. 69 Tahun 2010 tentang baku mutu limbah cair domestik kategori B dan kerusakan lingkungan hidup adalah $35 \mathrm{mg} / \mathrm{l}$.sedangkan hasil penelitian kadar TSS yang dilakukan dengan waktu kontak 5 jam, analisa dari hasil pengolahan yang telah dilakukan pada waktu kontak 5 jam, memenuhi syarat dan mampu menurunkan kadar TSS 97,44\% dengan waktu kontak 5 jam.Dalam proses pengolahan kadar TSS menerangkan bahwa kangkung yang digunakan dalam pengolahan dengan proses lahan basah dapat menurunkan kadar TSS sebesar $97,44 \%$ dari sampel awal yang ada pada limbah domestik RSUD Daya Kota Makassar.

\section{KESIMPULAN}

Berdasarkan hasil penelitian dan pembahasan yang telah dilakukan maka dapat ditarik kesimpulan sebagai berikut:

a. Proses aerasi dengan lahan basah dalam menurunkan kadar BOD pada air limbah RSUD Daya Kota Makassar menunjukan hasil yang baik karena telah mengalami penurunan kadar BOD yang dihasilkan memenuhi syarat yang sesuai dengan 
peraturan gubernur Sul-Sel no.69 tahun 2010.

b. Proses aerasi dengan lahan basah dalam menurunkan kadar TSS pada air limbah RSUD Daya Kota Makassar menunjukan hasil yang baik karena telah mengalami penurunan kadar TSS yang dihasilkan memenuhi syarat yang sesuai dengan peraturan gubernur Sul-Sel no.69 tahun 2010.

c. dengan hasil penurunan kadar BOD pada air limbah RSUD Daya Kota Makassar menunjukan hasil yang baik setelah melalui replikasi tiga kali dimana pada replikasi pertama $70,83 \mathrm{mg} / \mathrm{l}$ dengan persentasen penurunan $47,53 \%$ dan pada replikasi kedua mengalami penurunan dengan hasil 42,48 $\mathrm{mg} / \mathrm{l}$ denga persentase penurunan $68,53 \%$ begitupun dengan replikasi ke tiga dengan hasil penurunan 14,16 mg/l menunjukan persentase penurunan mencapai $89,51 \%$ sehingga kadar BOD yang dihasilkan memenuhi syarat yang sesuai dengan peraturan gubernur Sul-Sel no.69 tahun 2010.

dengan hasil penurunan kadar TSS pada air limbah RSUD Daya Kota Makassar menunjukan hasil yang baik setelah melalui replikasi tiga kali dimana pada replikasi pertama 40,66 mg/l dengan persentase penurunan $47,53 \%$ dan pada replikasi kedua mengalami penurunan dengan hasil 7,66 $\mathrm{mg} / \mathrm{l}$ dengan persentase penurunan $68,53 \%$ begitupun dengan replikasi ke tiga dengan hasil penurunan $1,66 \mathrm{mg} / \mathrm{l}$ menunjukan persentase penurunan mencapai 89,51\% sehingga kadar TSS yang dihasilkan memenuhi syarat yang sesuai dengan peraturan gubernur Sul-Sel no.69 tahun 2010.

\section{SARAN}

1. Bagi masyarakat agar kiranya dapat menggunakan tanaman kangkung untuk proses bioteknologi atau vitoremediasi untuk mengolah limbah domestik sebelum dibuang kebadan lingkungan agar lingkungan sekitar tidak tercemar.

2. Bagi RSUD Daya Kota Makassar agar lebih memperhatikan pengolahan limbah sebelum limbah dibuang ke badan lingkungan dan metode outlet wetland di sarankan diruangan terbuka serta mendapat cahaya matahari yang cukup untuk proses fotosintetis pada fitoremediasi.

\section{DAFTAR PUSTAKA}

Asmadi. 2013. Pengelolaan Limbah Medis Rumah Sakit. Yogyakarta: Gosyen Publishing.

Djoko Purwoko Dkk. 2016. Panduan Praktikum Kimia Lingkungan. Makassar: Poltekkes Jurusan Kesehatan Lingkungan.

Ign.Suharto. 2011. Limbah Kimia Dalam Pencemaran Udara Dan Air. Yogyakarta: Andi.

Lhisa Oktaviani. 2015. Proses Aerasi Dengan Metode Outlet Wetland Dalam Menurunkan Kadar Bod Pada Air Kanal Panampu. Makassar: Poltekkes Kemenkes Makassar. (KTI Tidak Diterbitkan).

Siregar.S. A. 2015. Instalasi Pengolahan Air Limbah. Yogyakarta: Pt. Kanisius.

Sugiharto. 2014. Dasar-Dasar Pengelolaan Air Limbah. Jakarta: Universitas Indonesia (Ui-Press).

Who 2003.Survei Pengolahan Air Limbah. (Http:/Www.Suarapembaruan.Com/News/2003/10/20/ Indeks. Html) diakses 13 Januari 2017). 